\title{
Biofunctionalized Capillary Flow Channel Platform Integrated with 3D Nanostructured Matrix to Capture Circulating Tumor Cells
}

\author{
Shashwat Banerjee \\ Actorius Innovations and Research (AIR) \\ Ganesh Khutale \\ Technological University Dublin \\ Vrushali Khobragade \\ Actorius Innovations and Research (AIR)
}

See next page for additional authors

Follow this and additional works at: https://arrow.tudublin.ie/nanolart

Part of the Medicinal-Pharmaceutical Chemistry Commons, and the Oncology Commons

\section{Recommended Citation}

Banerjee, S. S., Khutale, G. V., Khobragade, V., Kale, N. R., Pore, M., Chate, G. P., Jalota-Badhwar, A., Dongare, M., Khandare, J. J., Adv. Mater. Interfaces 2017, 4, 1600934.

This Article is brought to you for free and open access by the NanoLab at ARROW@TU Dublin. It has been accepted for inclusion in Articles by an authorized administrator of ARROW@TU Dublin. For more information, please contact arrow.admin@tudublin.ie, aisling.coyne@tudublin.ie,gerard.connolly@tudublin.ie.

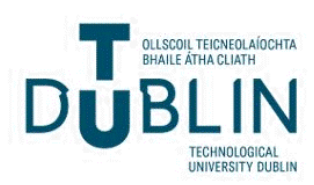


Authors

Shashwat Banerjee, Ganesh Khutale, Vrushali Khobragade, Narendra Kale, Milind Pore, Govind Chate, Archana Jalota-Badhwar, Manoj Dongare, and Jayant Khandare 


\title{
Biofunctionalized Capillary Flow Channel Platform Integrated with 3D Nanostructured Matrix to Capture Circulating Tumor Cells
}

\author{
Shashwat S. Banerjee,* Ganesh V. Khutale, Vrushali Khobragade, Narendra R. Kale, \\ Milind Pore, Govind P. Chate, Archana Jalota-Badhwar, Manoj Dongare, \\ and Jayant J. Khandare*
}

Circulating tumor cells (CTCs) from peripheral blood account genetic information for cancer diagnosis and overall disease monitoring. Analysis of "liquid biopsy" holds immense promise as it may lead to new approaches for cancer treatment. The study reports effective and continuous flow microchannel system for isolating CTCs using transferrin conjugated 3D matrix synthesized by crosslinking polyethylene glycol- $\mathrm{Fe}_{3} \mathrm{O}_{4}$ nanostructures for rapid and efficient capturing of CTCs. The platform provides option of using multiple microchannel units in series that can influence higher cell-capture efficiency due to increasing cell-substrate contact frequency. CTCs are captured with high efficiency even at low concentration of target cells $(-90 \%$ at 25 cells per $\mathrm{mL}$ blood). Furthermore, the study demonstrates that the cell-capture performance is influenced by topographic interactions between nanostructure based matrix and cancer cells of interest. In addition, this study demonstrates the "proof of concept" using 3D microchannel system having capacity of simultaneously capturing and permanently eliminating CTCs from peripheral blood samples. Further, the study evaluates clinical samples of colon and breast cancer patients for rapid isolation of CTCs. Conclusively, the present platform demonstrates inordinate capacity for cancer cell sorting, biological studies of CTCs, and cancer metastasis, potentially benefiting the real time liquid biopsy and early prognosis of cancer.

\section{Introduction}

Circulating tumor cells (CTCs) disseminate from the primary tumor and migrate in peripheral blood of cancer patients. ${ }^{[1-4]}$ CTCs play an important role in metastases and are primarily responsible for the growth of secondary tumors and spread of cancer in distant part of the body. ${ }^{[5-7]}$ Besides conventional diagnostic approaches (e.g., tumor biopsy, anatomical/molecular imaging, and serum marker detection), detecting CTCs in peripheral blood is of prognostic value to predict disease progression, response to treatment, relapse, and overall survival. ${ }^{[8-10]}$ However, the detection and characterization of CTCs have been technically challenging due to their extremely low occurrence $\left(10-100 \mathrm{~mL}^{-1}\right)$ among a high number $\left(10^{9}\right.$ cells $\left.\mathrm{mL}^{-1}\right)$ of hematologic cells in blood. ${ }^{[7,8]}$ In recent years, a diversity of diagnostic methods have been developed for CTC detection and enrichment that principally include immunomagnetic separation, ${ }^{[2,11]}$ microfluidic platforms, ${ }^{[8,12,13]}$ and microfilter devices..$^{[14]}$ Microfluidic approaches require precise control over operational parameters and often involve complex designs besides being slow due to lower fluid transfer rates, thus limiting them in time efficiency and high throughput analysis. On the other hand, immunomagnetic methods for separation of CTCs are simple to use but suffer relatively low separation efficiency and require pretreatment of blood to remove hematogenic cells. ${ }^{[15]}$ Food and Drug Administration-approved CellSearch Technology uses markers with immunomagnetic beads to isolate CTCs. To enhance CTC capturing efficiency and to reduce cost, researchers have been exploring new platforms including microrockets. ${ }^{[2,5,8,16,17]}$

Here, we report the use of glass capillary-flow channel functionalized with 3D antibody matrix impinged with magnetic nanoparticles for simultaneous isolation and detection of CTCs from clinical samples. Nanostructure materials such as nanopillars, graphene sheets, and nanoparticles enhance biomolecule

DOI: 10.1002/admi.201600934 


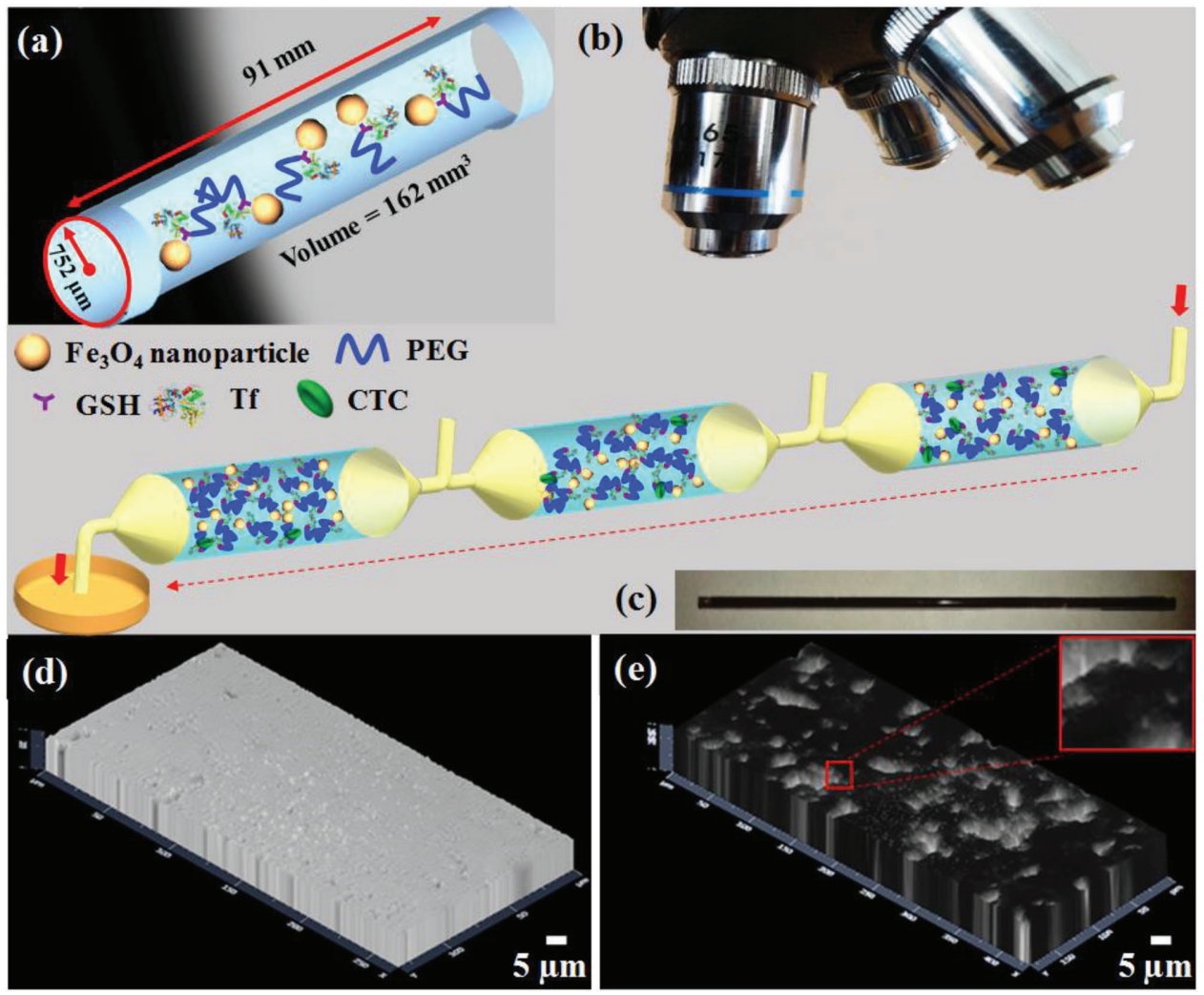

Figure 1. Schematic representation of the configuration and operational mechanism of multi-unit microchannel system for capturing circulating tumor cells (CTCs). a) 3D Fe $\mathrm{O}_{4}$-GSH-PEG-Tf matrix conjugated microchannel glass substrate with $91 \mathrm{~mm}$ of length, $1.55 \mathrm{~mm}$ of diameter, and $162 \mathrm{~mm}$ volume. b) Cancer patient's blood sample is fed in the first 3D microchannel capillary to capture CTCs. Subsequently, blood with the uncaptured cells from the first microchannel is then fed to the second microchannel capillary and similarly to the third microchannel capillary. Finally, the CTC capturing efficiency is calculated using the set of three cycles. Intermediate outlets between microchannels enable cell capture efficiency estimation of individual microchannels. c) $\mathrm{Fe}_{3} \mathrm{O}_{4}$-GSH-PEG-Tf matrix conjugated glass capillary image. d) Pseudo-3D electron microscopy images of glass capillary and e) $\mathrm{Fe}_{3} \mathrm{O}_{4}$-GSH-PEG-Tf conjugated glass capillary demonstrating 3D surface on CTC substrate using Zeiss Zen software.

recognition. ${ }^{[18]}$ Most of these CTC capturing platforms are limited by single unit operations. Therefore, we hypothesized that integrating a flow-channel unit system such as glass capillary with a patterned 3D matrix based on nanostructured materials will offer unique advantages such as (i) better cell-substrate contact frequency leading to enhanced CTC capture due to the 3D matrix and high surface to volume ratio of glass capillary, (ii) opportunity of using multiple units in series for higher cell capture efficiency and sensitivity, (iii) user flexibility to adjust the number of capillary units that best fit his particular assay, and (iv) also the capillaries with different coatings and targeting moieties can be applied simultaneously for isolating CTCs based on specific affinity as well as to sort them as they often exist with many subtypes by multiple isolation steps. Glassbased materials have been widely accepted in applications such as cell fixing substrates and as promising biocompatible materials. ${ }^{[19,20]}$ However, the glass-based materials suffer from other disadvantages such as low cell affinity. To overcome this, most existing technologies rely on chemical modification to render the inert surfaces bioactive. ${ }^{[20]}$

In study we principally employed HCT116 colon cancer cells overexpressing transferrin-receptors (TfRs) to probe the capture efficiency of capillary flow-cell platform. Thus advantages of our platform are: (1) nanoprotrusions generated by Poly(ethylene glycol)-iron oxide $\left(\mathrm{PEG}-\mathrm{Fe}_{3} \mathrm{O}_{4}\right)$ functionalized "Transferrinconjugated Nanostructured Matrix on Silane-Functionalized Glass Capillary" (Tf-NMSFGC) increases the topographic interactions between cancer cells and substrate as depicted in Figure 1. (2) The dimensions of the platform mediate high density packing of $\mathrm{PEG}-\mathrm{Fe}_{3} \mathrm{O}_{4}$-Tf on NMSFGC, which results in increased local concentration of Tf, and (3) optimized multicomponent 3D matrix with tunable architecture by application of PEG to cross-link $\mathrm{Fe}_{3} \mathrm{O}_{4}$ nanoparticles. The length of the capillary flow channel was $91 \mathrm{~mm}$ while the volume was $162 \mathrm{~mm}^{3}$. These aspects of capillary flow channel 3D system synergistically contribute to enhance capture of cancer cells.

\section{Results and Discussion}

The 3D nanostructured matrix was synthesized through a multistep process (Figure 2). First, the cross-linked matrix of $\mathrm{PEG}-\mathrm{Fe}_{3} \mathrm{O}_{4}$ was obtained according to our recent procedure. ${ }^{[17]}$ Second, the resulting $\mathrm{PEG}-\mathrm{Fe}_{3} \mathrm{O}_{4}$ was functionalized with specific targeting ligand Tf and then chemically immobilized to the amine-functionalized silanated glass through the reactive carboxyl group of the glutathione (GSH) linker using $N$-(3-dimethylaminopropyl)-N-ethylcarbodiimide $\mathrm{HCl}$ 

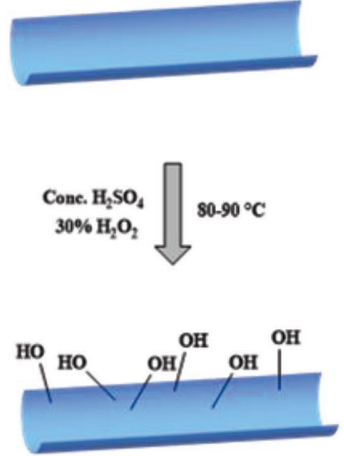<smiles>CCO[Si](CCCN)(OCC)OCC</smiles>

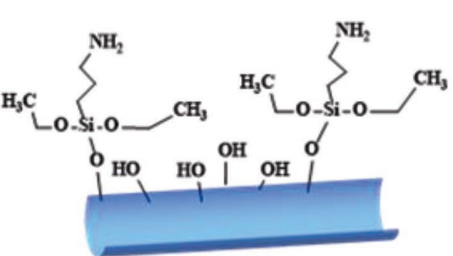

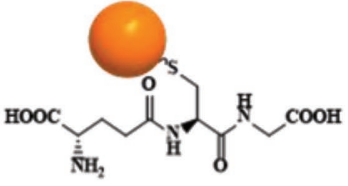

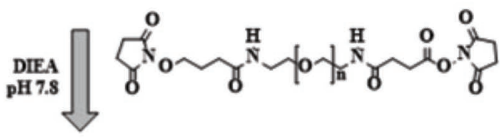

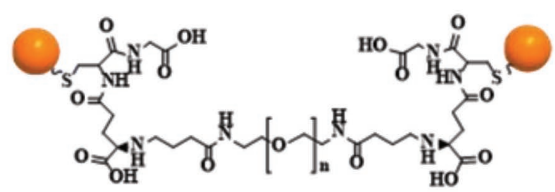

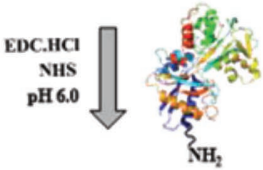
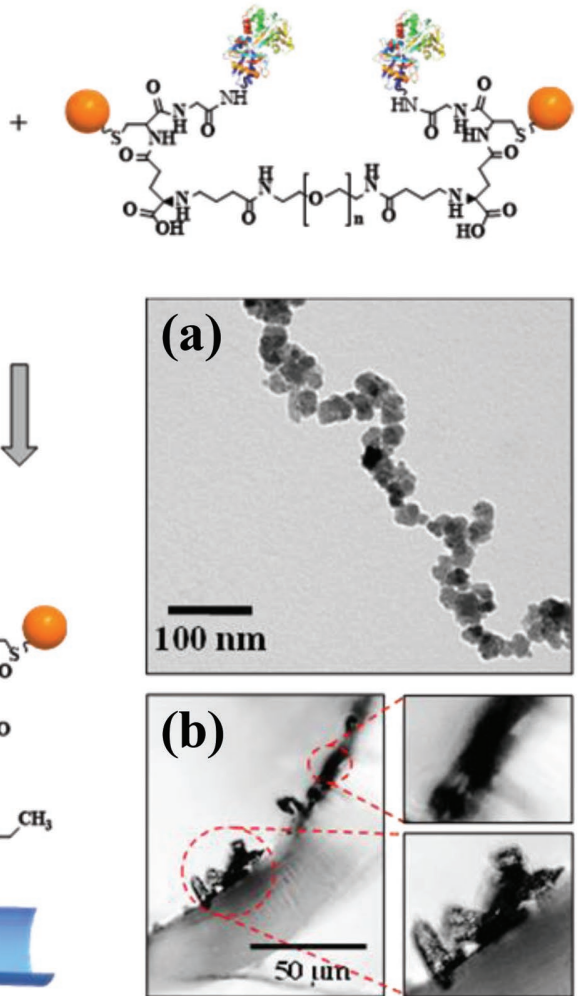

Figure 2. Synthetic scheme of Tf-NMSFGC microchannel system. a) TEM image of the branched structure where multiple $\mathrm{Fe}_{3} \mathrm{O}_{4}$ nanoparticles are cross-linked by PEG chains forming a 3D matrix. b) Optical image of a cross-section of Tf-NMSFGC substrate. The average thickness of the matrix (shown by a dotted red circle) estimated from the images was $11 \pm 1 \mu \mathrm{m}$ and few isolated aggregates with thickness $\sim 34 \pm 1 \mu \mathrm{m}$ were also present.

(EDC $\cdot \mathrm{HCl})$ coupling reaction. An amide linkage was formed between the carboxyl group of $\mathrm{PEG}-\mathrm{Fe}_{3} \mathrm{O}_{4}$ and the amine group of silane. Finally, the unreacted components on the glass substrate were removed by a series of washings with Milli-Q water. It was noted that $\approx 2.0 \mathrm{mg} \mathrm{Fe}_{3} \mathrm{O}_{4}$-GSH-PEG-Tf was chemically deposited on the glass substrate. Consequently, a flow-channel system with $\mathrm{Fe}_{3} \mathrm{O}_{4}$-GSH-PEG-Tf $3 \mathrm{D}$ matrix of $\approx 91 \mathrm{~mm}$ long chaotic mixing channel ( $o d=1.82$ and $i d=1.55 \mathrm{~mm}$ ) was produced. The amount of amine groups on the silanized glass surface was estimated to be $\approx 16 \mathrm{~nm}^{-2}$. The anchoring of the $\mathrm{Fe}_{3} \mathrm{O}_{4}$-GSH-PEG-Tf matrix on the silane-functionalized glass was found to be strong, as the Tf-NMSFGC platform could survive multiple cycles of washings and drying. Figure 2 (inset) shows a typical transmission electron microscopy (TEM) 
image of the PEG- $\mathrm{Fe}_{3} \mathrm{O}_{4}$ matrix, which confirms the crosslinking of the $\mathrm{Fe}_{3} \mathrm{O}_{4}$ nanoparticles through the PEG chains, thereby leading to 3D nanoscale architecture. The darker parts in the image result from the $\mathrm{Fe}_{3} \mathrm{O}_{4}$ particles as they are more electron-dense than the PEG chains. The mean size of $\mathrm{Fe}_{3} \mathrm{O}_{4}$ nanoparticles in the matrix was estimated to be $\approx 24 \pm 8 \mathrm{~nm}$, which corroborates well with their starting size. It also suggests that the conjugation reaction did not alter the morphology of the particles. Furthermore, the nanosystem was characterized by Fourier Transform Infrared (FTIR) spectroscopy to verify successful conjugation of PEG and Tf to $\mathrm{Fe}_{3} \mathrm{O}_{4}-\mathrm{GSH}$ (Figure S1, Supporting Information). The IR spectrum of $\mathrm{Fe}_{3} \mathrm{O}_{4}-\mathrm{GSH}$ showed peaks at $1630,1542,1390$, and $890 \mathrm{~cm}^{-1}$ corresponding to $\mathrm{C}-\mathrm{N}$ and $\mathrm{Fe}-\mathrm{O}$ bonds, respectively. The IR spectrum of $\mathrm{Fe}_{3} \mathrm{O}_{4}$-GSH-PEG and $\mathrm{Fe}_{3} \mathrm{O}_{4}$-GSH-PEG-Tf showed additional peak at $1262 \mathrm{~cm}^{-1}$ due to $\mathrm{C}-\mathrm{O}$ stretch and resulted from the presence of PEG. The IR spectrum of $\mathrm{Fe}_{3} \mathrm{O}_{4}$-GSH-PEG-Tf showed new peak at $1542 \mathrm{~cm}^{-1}$ confirming conjugation of $\mathrm{Tf}$ with $\mathrm{Fe}_{3} \mathrm{O}_{4}$-GSH-PEG. ${ }^{[17]}$

The flow-channel substrate was evaluated by analyzing the cross-section of the NMSFGC substrate (Figure 2, inset). The average thickness of the matrix (shown by the dotted red circle) was estimated to be $\approx 11 \pm 1 \mu \mathrm{m}$ from the TEM image. A few isolated aggregates with thickness $\approx 34 \pm 1 \mu \mathrm{m}$ were also present. The amount of matrix covering the flow-channel surface was estimated to be $\approx 2.0 \pm 0.2 \mathrm{mg}$. Furthermore, the matrix was found to cover $90 \%$ of the surface when evaluated using optical microscopy and ImageJ software (Figure 3). On the other hand, the density of Tf on the Tf-NMSFGC matrix was estimated to be $\approx 285 \mathrm{mg} \mathrm{g}^{-1}$ by a modified Bradford procedure.

The performance of this integrated flow-channel glass substrate system was evaluated at first using TfR-positive HCT116

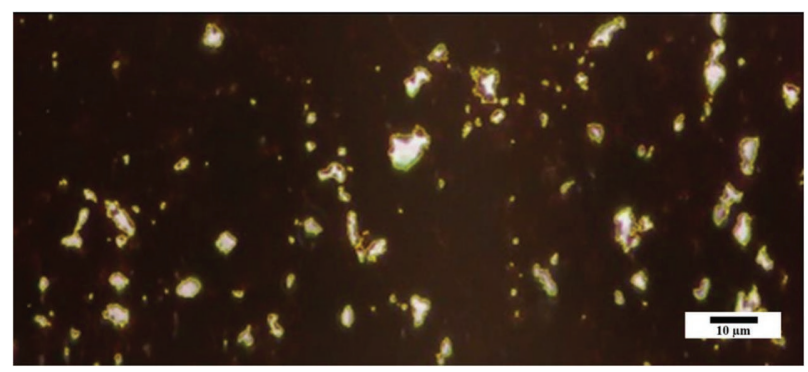

Figure 3. Optical microscopy image of microchannel system coated with $\mathrm{Fe}_{3} \mathrm{O}_{4}$-GSH-PEG-Tf matrix $(2.0 \mathrm{mg})$.

cells. As shown in Figure 4, a 15 min incubation using the TfNMSFGC flow-channel system showed excellent cell-capture efficiency of $>95 \%$ (Figure 5a). Two control experiments based on identical design features (1) without $\mathrm{Fe}_{3} \mathrm{O}_{4}$-GSH-PEGTf matrix on flow-channel device surface and (2) NMSFGC without Tf were also evaluated. As shown in Figure 5a, the flow-channel system without $\mathrm{Fe}_{3} \mathrm{O}_{4}$-GSH-PEG-Tf matrix and NMSFGC showed significantly less cell attachment of $5 \%$ and $52 \%$, respectively. Thus, the (complete) Tf-NMSFGC flowchannel system showed $\approx 19$ times and times higher cancer cell-capture efficiency as compared with flow-channel systems without $\mathrm{Fe}_{3} \mathrm{O}_{4}$-GSH-PEG-Tf matrix and NMSFGC without Tf, respectively. The results clearly confirm that the cancer cellcapture efficiency of the system without $\mathrm{Fe}_{3} \mathrm{O}_{4}$-GSH-PEG-Tf matrix was significantly less, suggesting that both $\mathrm{Fe}_{3} \mathrm{O}_{4}-\mathrm{GSH}$ PEG matrix and Tf were crucial for enhanced performance. The capture efficiency of Tf-NMSFGC was further investigated with increasing order of cell concentrations of 25, 50, and 100 cells $\mathrm{mL}^{-1}$ (Figure 5b). Tf-NMSFGC was found to

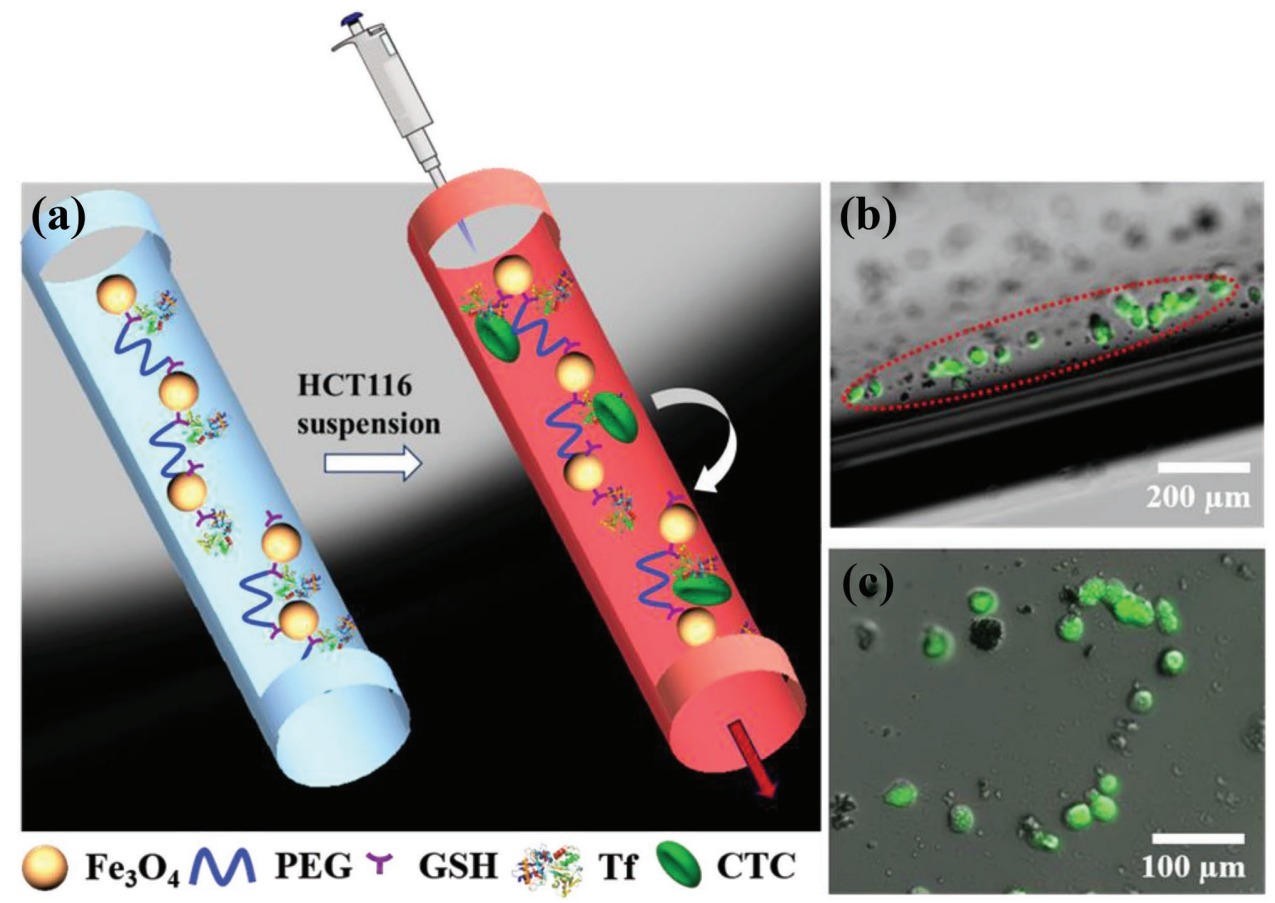

Figure 4. a) Schematic representation of HCT116 cells captured from cell medium on 3D Tf-NMSFGC microchannel system. b,c) Fluorescence images of HCT116 cells captured from cell medium on 3D Tf-NMSFGC microchannel system after 15 min incubation. 
(a)

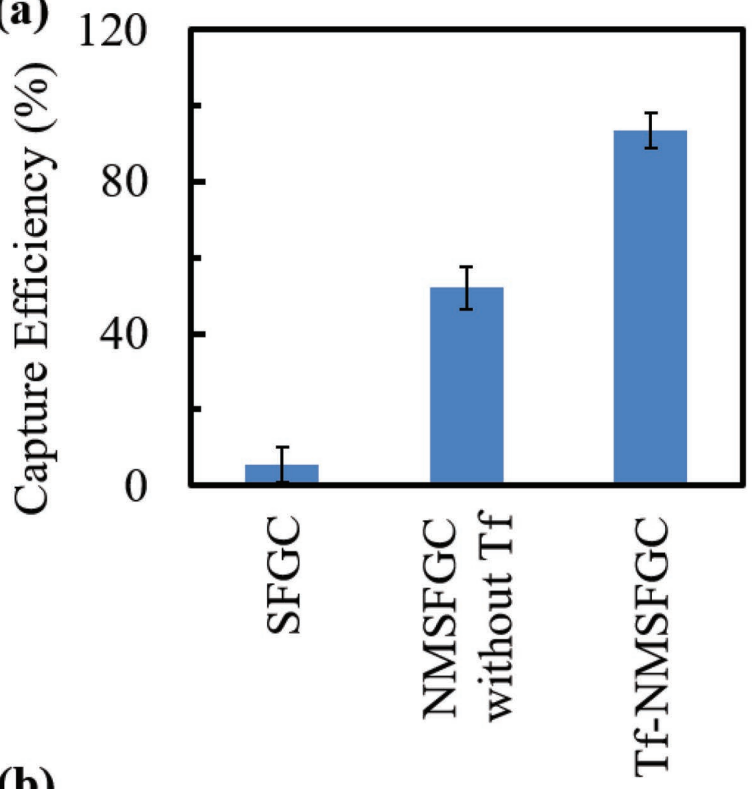

(b)

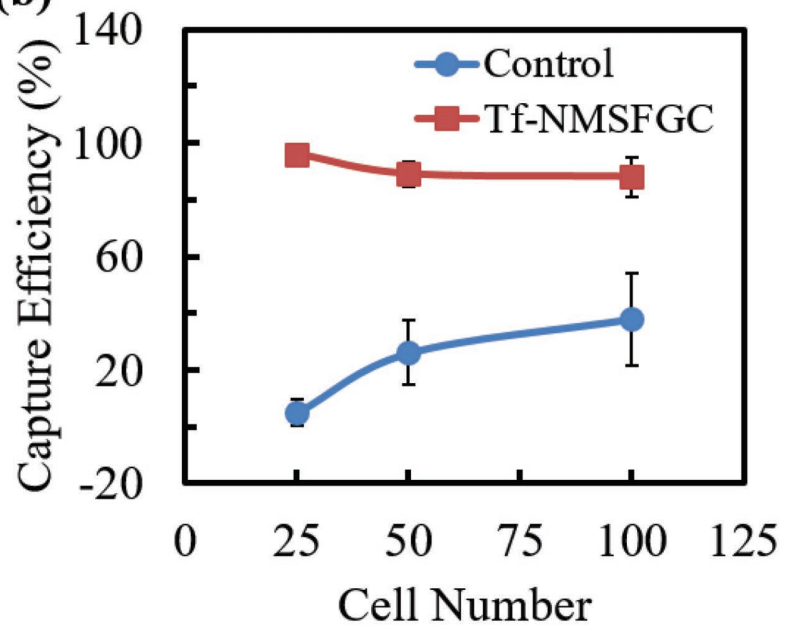

Figure 5. a) $\mathrm{CTC}$ capture efficiency of $\mathrm{Fe}_{3} \mathrm{O}_{4}$ - $\mathrm{CSH}$-PEG-Tf coated microchannel system in cell medium ( $n=3)$. b) CTC capture efficiency of $\mathrm{Fe}_{3} \mathrm{O}_{4}$ GSH-PEG-Tf and $\mathrm{Fe}_{3} \mathrm{O}_{4}$-GSH-PEG (control) coated microchannel system in cell medium having different cell concentration $(n=3)$.

capture $96 \%, 89 \%$, and $88 \%$ cells, respectively, demonstrating that the cell-capture efficiency showed a similar trend even at higher cell concentrations. Interestingly, the highest CTC efficiency was achieved with the lower number of cells (i.e., for 25 cells concentration $\mathrm{mL}^{-1}$ ). This might be due to the optimal cell number and the optimized available surface area in flowchannel substrate. Furthermore, it was found that the captured cells remained intact for $\approx 24 \mathrm{~h}$ and could be used for further studies (Figure 6).

To further investigate the influence of $\mathrm{Fe}_{3} \mathrm{O}_{4}$-GSH-PEG-Tf matrix on cell capture efficiency, the flow-channel system was functionalized with different amounts of matrix $(0.7-2.0 \mathrm{mg}$ per glass capillary) and then evaluated for capturing HCT116 cancer cells. The study showed that the cell capture efficiency increased with increasing amount of 3D matrix (Figure 7). The capture efficiency increased from $48 \%$ to $96 \%$ when the matrix
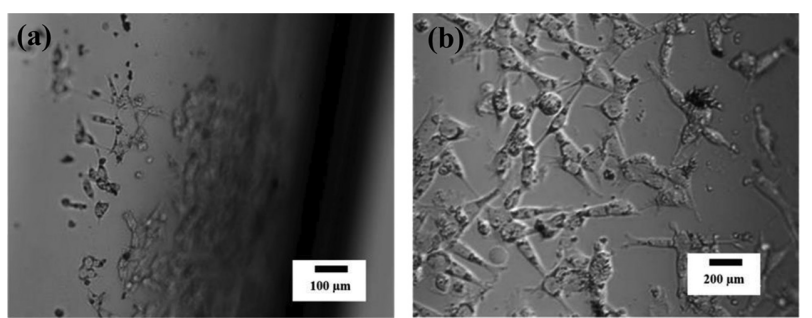

Figure 6. Images of $\mathrm{HCT1} 16$ cells captured on Tf-NMSFGC microchannel system after 24 h. a) 10× magnification and b) 20× magnification.

amount increased from 0.7 to $2.0 \mathrm{mg}$. Thus, the flow-channel system with higher matrix amount $(2.0 \mathrm{mg})$ showed two fold increase in capture efficiency for HCT116 cells as compared to the system with lower amount $(0.7 \mathrm{mg})$. This difference further verified the contribution of the matrix in improving cell anchorage due to enhanced topographic interactions between the $\mathrm{Fe}_{3} \mathrm{O}_{4}$-GSH-PEG-Tf matrix and the surface of the cancer cells, leading to the enhanced cell capture.

Furthermore, capability of the flow-channel system to capture rare tumor cells was validated using bio-simulated CTC samples. The sample was prepared by spiking Green Flurescencent Protein (GFP) labeled HCT116 cells into whole (human) blood with concentrations of about 25 cells $\mathrm{mL}^{-1}$. For comparison, capture efficiency was also evaluated in lysed blood spiked with similar concentrations of HCT116 cells. After 15 min incubation of the bio-simulated CTC sample in Tf-NMSFGC flow-channel system, HCT116 cells were found to be attached to the $\mathrm{Fe}_{3} \mathrm{O}_{4}$-GSH-PEG-Tf matrix as shown in Figure $8 \mathrm{a}-\mathrm{c}$. The $3 \mathrm{D}$ images of the flow-channel system incubated with spiked blood sample clearly revealed immobilization of the HCT116 cells on $\mathrm{Fe}_{3} \mathrm{O}_{4}$-GSH-PEG-Tf matrix, thus confirming the cell capture due to the presence of nanostructurebased matrix (Figure 8d). The CTC capture efficiency in Red Blood Cell (RBC) lysed blood was $92 \%$, and in intact peripheral blood was $88 \%$ (Figure 8e), comparable to the capture efficiency in McCoy medium (96\%). It can be observed that Tf-NMSFGC flow-channel system could efficiently capture HCT116 cells in all cases. The capture efficiencies were comparable and did not have significant differences regardless of whether the red blood cells were lysed or intact. These results clearly suggest that complex conditions had no significant effects on the cancer cell

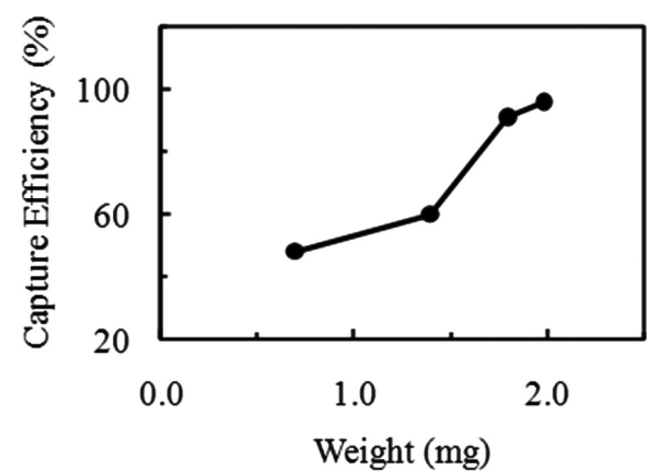

Figure 7. Effect of $\mathrm{Fe}_{3} \mathrm{O}_{4}$-GSH-PEG-Tf matrix concentration on cell capture efficiency from medium having 25 cells $\mathrm{mL}^{-1}$. 
www.advmatinterfaces.de
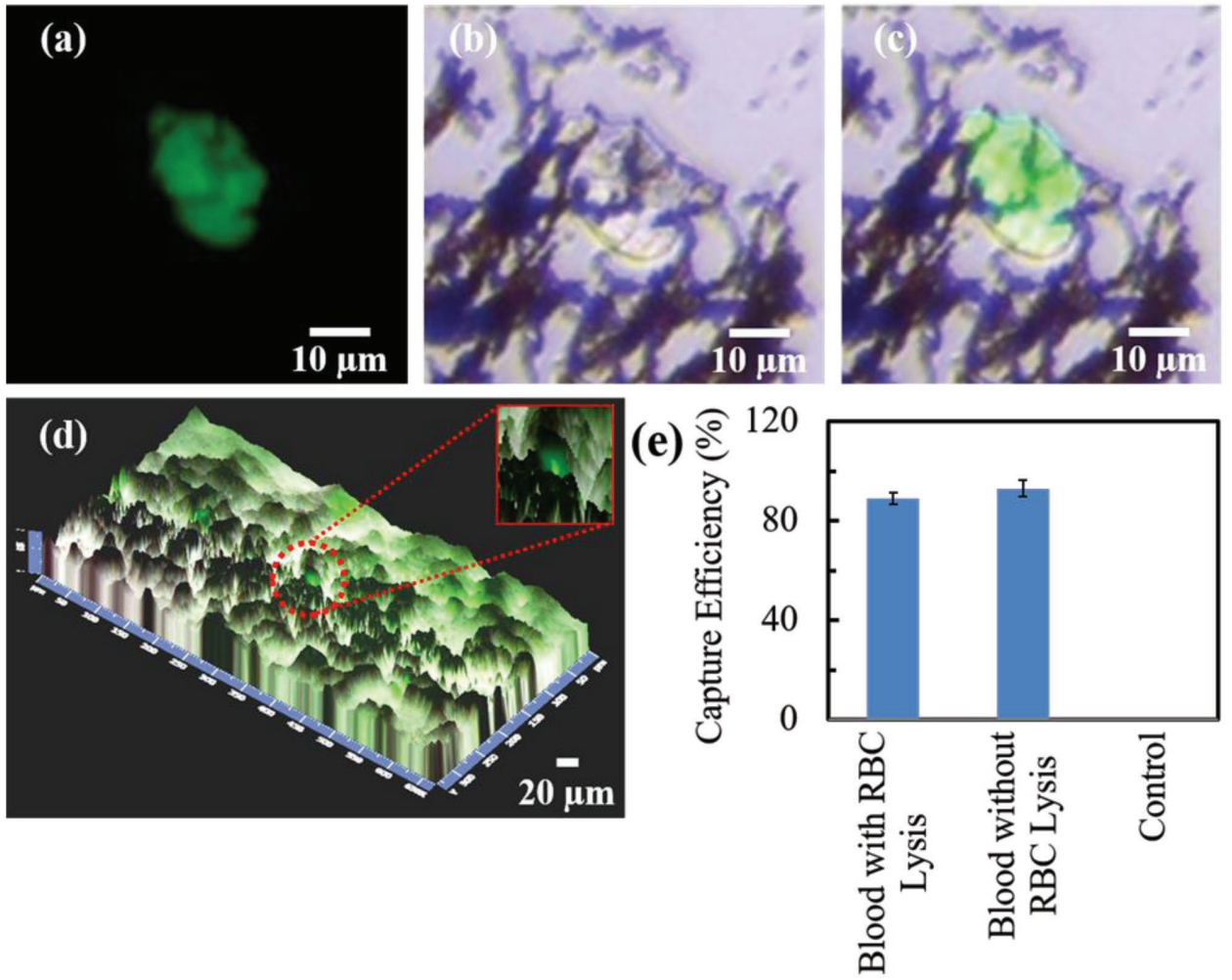

Figure 8. a-c) Bright field and fluorescent images of HCT116 cells captured from spiked blood on 3D Tf-NMSFGC microchannel system after 15 min incubation. d) Pseudo-3D image of CTCs captured on $\mathrm{Fe}_{3} \mathrm{O}_{4}$-GSH-PEG-Tf coated capillary. e) CTC capture efficiency of Fe $\mathrm{O}_{3} \mathrm{O}_{4}$-GSH-PEG-Tf coated capillary in whole blood with RBC lysis, without RBC lysis, and in culture media $(n=3)$.

capturing ability and Tf-NMSFGC flow-channel system can be directly used in whole blood.

After confirming that the Tf-NMSFGC flow-channel system with the matrix can rapidly and efficiently capture tumor cells, we translated the system to study clinical samples from three cancer patients' peripheral blood (including colon and breast cancer patients). As in control, blood was also processed from healthy individuals. Cells were identified as CTCs when stained positive for tumor markers cytokeratin (CK18) and DNA interacting probe (4,6-diamidino-2-phenylindole i.e. DAPI) and negative for leukocyte markers (CD45). The images of CTCs captured from clinical samples with our method from $0.1 \mathrm{~mL}$ of blood are shown in Figure 9. As shown in the image, CTCs exhibited strong CK staining and DAPI staining confirming intact nuclei in the captured cells. Conversely, no CTC was found in any healthy samples, suggesting that the Tf-NMSFGC flow-channel system can be successfully applied to real patient blood samples. We anticipate the capture of CTCs from cancer patients having anti-epithelial cell adhesion molecules (EpCAM). Further study in this direction with greater numbers of clinical samples is currently in progress. Our system exhibited excellent capacity in capturing CTCs as it offers flexibility of using 3D flow-channel system units in series for cancer cell capture, which is otherwise not easy to be captured from one cycle. A continuous microflow-system in controlling the feed and output using patient's sample is currently being designed and evaluated.

\section{Conclusions}

We developed a new-generation flow-channel system by synergistically incorporating $\mathrm{Fe}_{3} \mathrm{O}_{4}$-GSH-PEG-Tf nanostructured 3D matrix by chemical conjugation. This unique flow-channel system combines simple flow-channel system with a 3D nanostructured matrix to produce a synergistic effect of enhanced cell-substrate contact frequency as well as affinity. The resulting flow-channel system exhibited efficient and rapid (within 15 min) CTC-capturing ability in both cell medium and in spiked blood samples. Furthermore, the system was successfully employed for detecting cancer patient's clinical peripheral blood samples, endorsing their clinical potential in CTC studies. We envision that the novel flow-channel will open new opportunities for early diagnosis of cancer metastasis as well as recovery of other rare cells, proteins, DNA, and from biological specimens.

\section{Experimental Section}

Reagents: Bis-NHS-PEG, EDC.HCl, N,N-diisopropyl ethylamine (DIPEA), ferric chloride tetrahydrate, ferrous chloride hexahydrate, and transferrin (Tf) were purchased from Sigma-Aldrich (St. Louis, $\mathrm{MO}$ ). $\mathrm{GSH}$ and $\mathrm{N}$-hydroxysuccinimide (NHS) were procured from Sigma-Aldrich Chemical Co. (Germany). Milli-Q water, obtained from a Millipore water purification system (Merck Millipore, India), was used throughout the study. All chemicals were of the analytical grade and were used without further purification. 

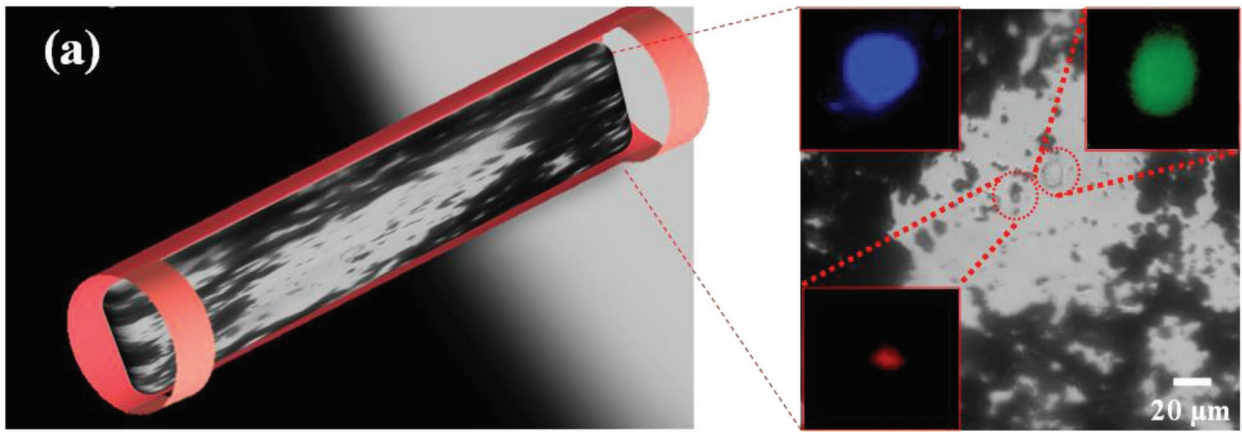

(b)
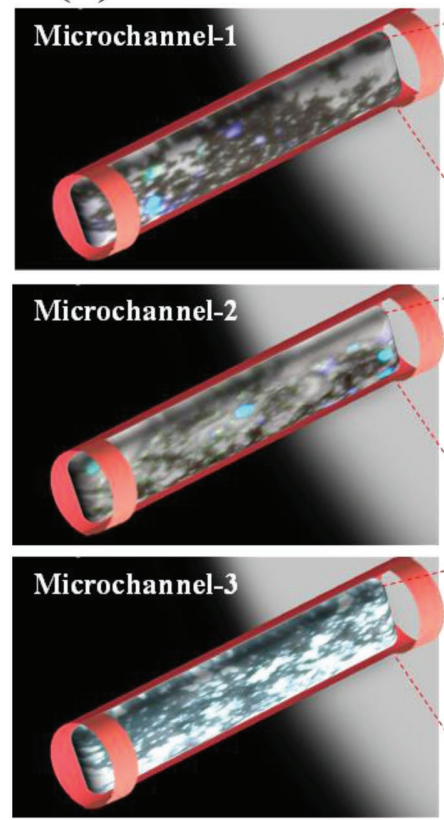

Schematic
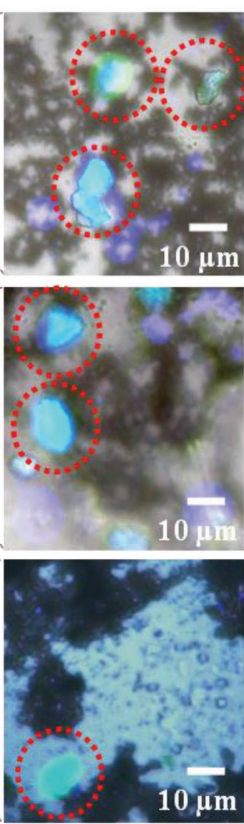

Merged
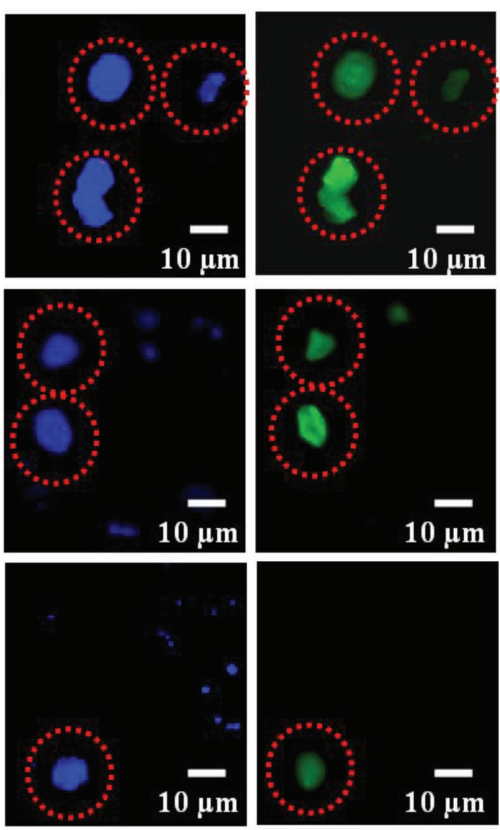

Nuclear (DAPI)

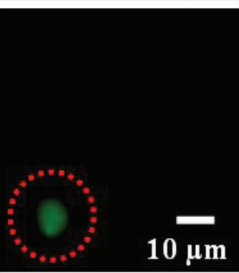

CK18 (FITC)

Figure 9. Bright field and fluorescent images of CTCs captured from blood samples of a colon cancer patient. a) Immunocytochemistry method based on Flurescein Isothiocyanate-labeled anti-cytokeratin (green), PE-labeled anti-CD45 (red), and DAPI (blue) nuclear staining was applied to identify and enumerate $\mathrm{CTCs}$ on $\mathrm{Fe}_{3} \mathrm{O}_{4}$ - $\mathrm{CSH}$-PEG-Tf coated capillary. The florescence images were acquired in 3D capillary at different planar positions with highest intensity. b) Bright field and fluorescent merged images of CTCs captured on 3D microchannel system in series.

Synthesis of $\mathrm{Fe}_{3} \mathrm{O}_{4}$ - $\mathrm{GSH}$ Conjugate: $\mathrm{Fe}_{3} \mathrm{O}_{4}$ nanoparticles were synthesized by co-precipitation of $\mathrm{Fe}^{2+}$ and $\mathrm{Fe}^{3+}$ ions using ammonia base followed by hydrothermal ripening of nanoparticles. ${ }^{[21]}$ For typical nanoparticle functionalization reaction, $500 \mathrm{mg}$ of $\mathrm{Fe}_{3} \mathrm{O}_{4}$ was dispersed in $15 \mathrm{~mL}$ Milli-Q water and $5 \mathrm{~mL}$ methanol by sonication for $15 \mathrm{~min}$. $400 \mathrm{mg}$ of $\mathrm{GSH}$ was dissolved in Milli-Q water and mixed with $\mathrm{Fe}_{3} \mathrm{O}_{4}$ solution. The mixture was then re-sonicated for $2 \mathrm{~h}$. $\mathrm{Fe}_{3} \mathrm{O}_{4}-\mathrm{GSH}$ was then isolated by magnetic separation, washed with repeated cycles of excess Milli-Q water, and dried under vacuum.

Synthesis of $\mathrm{Fe}_{3} \mathrm{O}_{4}$-GSH-PEG Conjugate: $120 \mathrm{mg}$ of bis[2-(Nsuccinimidyl-succinylamino) ethyl]polyethylene glycol (Bis-NHS-PEG; $3 \mathrm{kDa}$ ) was dissolved in $6 \mathrm{~mL}$ of Milli-Q water and was allowed to react with $30 \mathrm{mg}$ of $\mathrm{Fe}_{3} \mathrm{O}_{4}-\mathrm{GSH}$ in the presence of $100 \mu \mathrm{L}$ of 1000 ppm DIPEA at a final solution $\mathrm{pH}$ of 7.8. The reaction mixture was continuously stirred at room temperature for $24 \mathrm{~h}$. $\mathrm{Fe}_{3} \mathrm{O}_{4}-\mathrm{GSH}$-PEG was then isolated by magnetic separation, washed with repeated cycles of excess Milli-Q water, and dried under vacuum.

Synthesis of Tf-PEG-CSH- $\mathrm{Fe}_{3} \mathrm{O}_{4}: 40 \mathrm{mg}$ of PEG-CSH- $\mathrm{Fe}_{3} \mathrm{O}_{4}$ was first gently stirred in the presence of $200 \times 10^{-3} \mathrm{M} \mathrm{EDC} \cdot \mathrm{HCl}$ and $200 \times 10^{-3} \mathrm{M} \mathrm{NHS}$ at $\mathrm{pH} \sim 6.0$ for $15 \mathrm{~min}$ to activate the carboxyl groups at room temperature. Next, $10 \mathrm{mg}$ of Tf was incubated with activated
PEG-CSH- $-\mathrm{Fe}_{3} \mathrm{O}_{4}$ for $4 \mathrm{~h}$ at room temperature, then washed with Milli-Q water, and finally dried.

Functionalization of Glass Capillary: Commercially available glass capillaries were activated in hot $\left(80-90^{\circ} \mathrm{C}\right)$ piranha solution $\left(\mathrm{H}_{2} \mathrm{O}_{2}\right.$ (30\%): $\mathrm{H}_{2} \mathrm{SO}_{4}$ ) (1:3) for $2 \mathrm{~h}$. The treated glass capillaries were then rinsed thoroughly with Milli-Q water and dried under vacuum at room temperature. Silanization of the glass capillary surface was carried out by treating the glass with (3-aminopropyl) triethoxysilane in toluene $3 \%$ solution) at room temperature for $24 \mathrm{~h}$. The glass substrates were rinsed with toluene and Milli-Q water, respectively, and the density of the amine groups on the silanized glass surface was estimated by a colorimetric assay reported by Noel et al. ${ }^{[22]}$ Five different silanized substrates were measured to estimate the average density of amine groups on the silanized surfaces.

Anchoring $\mathrm{Fe}_{3} \mathrm{O}_{4}$-GSH-PEG-Tf Matrix on Silane-Functionalized Glass Capillary: First, the carboxyl group in the GSH linker of $\mathrm{Fe}_{3} \mathrm{O}_{4^{-}}$ GSH-PEG-Tf $(10 \mathrm{mg})$ was activated in $3 \mathrm{~mL}$ solution of $200 \times 10^{-3} \mathrm{M}$ $\mathrm{EDC} \cdot \mathrm{HCl}$ and $200 \times 10^{-3} \mathrm{M} \mathrm{NHS}$ with gentle shaking for $15 \mathrm{~min} .10 \mu \mathrm{L}$ of $\mathrm{Fe}_{3} \mathrm{O}_{4}$-GSH-PEG-Tf solution was passed through the inert part of silanized glass capillary and the capillary was rolled for $2 \mathrm{~min}$ for uniform coating. This step was repeated twice and finally the film was 
dried under vacuum at room temperature. The coated glass capillary (NMSFGC) was then repeatedly washed with Milli-Q water to remove any noncovalently attached material and again re-dried under vacuum at room temperature.

Cell Culture and Patients: HCT116 cells (ATCC) were cultured in McCoy's cell culture medium (Invitrogen) supplemented with 10\% fetal calf serum (Invitrogen), 100 units penicillin (Invitrogen), and $100 \mu \mathrm{g} \mathrm{mL} \mathrm{m}^{-1}$ streptomycin (Invitrogen) in $25 \mathrm{~cm}^{2}$ flask. After incubation for $4 \mathrm{~d}$ at $37{ }^{\circ} \mathrm{C}$ and $5 \% \mathrm{CO}_{2}$, cells were trypsinized, stained with $1 \times$ Trypan blue, and counted using Neubauer chamber. Blood from healthy volunteer was obtained by strictly following protocols and guidelines of the ethics committee. All cancer patient samples included in this study were collected at Manik Hospital and Research Center, Aurangabad, India with their informed consent. The Manik Hospital and Research Center ethics committee approved the study and consent forms. The conducted study strictly adhered to the approved protocols and the guidelines of the ethics committee.

Capture of Cancer Cells in McCoy Medium: Preliminary studies revealed that the optimal volume of the glass capillary to hold cell medium was $100 \mu \mathrm{L}$. This optimal condition was employed in further studies for CTC capture and isolation from McCoy medium. $100 \mu \mathrm{L}$ of McCoy medium containing low concentration of HCT116 cells $\left(25\right.$ cells $\mathrm{mL}^{-1}$ ) was introduced in Tf-NMSFGC using micropipette and then rolled inside the capillary for $5 \mathrm{~min}$ in order to initiate the interaction between the cells and $\mathrm{Fe}_{3} \mathrm{O}_{4}$-GSH-PEG-Tf. After $5 \mathrm{~min}$ the sample was collected from the capillary using micropipette and transferred to another Tf-NMSFGC and again rolled inside it for another $5 \mathrm{~min}$. This procedure was repeated one more time. The sample was then collected in 96 -well plates using micropipette. The capillaries were rinsed with PBS at least three times in order to remove unattached cells. The number of uncaptured cells was counted using the Zeiss Axio Observer Al fluorescence microscope. Also, the capture efficiency in medium with different cell concentrations of $\approx 25,50$, and 100 cells $100 \mu \mathrm{L}^{-1}$ was also evaluated.

Capture of Cancer Cells from Cancer Cell-Spiked Blood Samples: 25 dual fluorescent HCT116 cells were spiked in $100 \mu \mathrm{L}$ of blood from healthy person. Then the blood was lysed using RBC lysis buffer using 1:3 blood:RBC lysis buffer proportion. The sample was incubated at room temperature on rotator at $50 \mathrm{rpm}$ for $5 \mathrm{~min}$, followed by centrifugation at $2000 \mathrm{rpm}$ for $3 \mathrm{~min}$. The supernatant was discarded and pellet was re-suspended in $100 \mu \mathrm{L}$ PBS. This PBS was inserted in Tf-NMSFGC and rolled inside the capillary for $5 \mathrm{~min}$ in order to initiate the artificial CTC sample and $\mathrm{Fe}_{3} \mathrm{O}_{4}$-CSH-PEG-Tf interaction. After 5 min the sample was collected from the capillary using micropipette and transferred to another Tf-NMSFGC and rolled inside it for another $5 \mathrm{~min}$. This procedure was repeated one more time. The sample was then collected in 96-well plates using micropipette followed by rinsing of the capillaries with PBS at least three times. The number of uncaptured cells was counted using the Zeiss Axio Observer A1 fluorescence microscope fluorescence microscope.

Capture of CTC Cells from Clinical Colon Cancer Patient Sample: Peripheral blood obtained from clinically advanced cancer patients (including colon and breast cancer patients) in the age group of 45-60 years was used for the experiment. $1 \mathrm{~mL}$ of the blood was lysed in $3 \mathrm{~mL}$ RBC lysis buffer at room temperature for $15 \mathrm{~min}$ on rotator at $50 \mathrm{rpm}$. The sample was centrifuged at $2000 \mathrm{rpm}$ for $15 \mathrm{~min}$ at room temperature. The supernatant was discarded and pellet was resuspended in $500 \mu \mathrm{L}$ PBS. This was followed by fixation of the sample by incubating with $4 \%$ paraformaldehyde $(500 \mu \mathrm{L})$ for $10 \mathrm{~min}$ on rotator at $50 \mathrm{rpm}$. The sample was then centrifuged at $2000 \mathrm{rpm}$ for $15 \mathrm{~min}$ at room temperature. The supernatant was discarded and pellet was resuspended in $300 \mu \mathrm{L}$ PBS. Finally, the sample was stained with anitcytokeratin 18 (Abcam) and anti CD45 antibodies (Santa Cruz Biotechnology) for $1 \mathrm{~h}$ at room temperature and DAPI $\left(0.5 \mathrm{mg} \mathrm{mL}^{-1}\right)$ for $10 \mathrm{~min}$ at room temperature and visualized in 96-well plates under the fluorescence microscope (Zeiss Axio Observer A1 fluorescence microscope). After confirming that the stained/tested blood fraction contains cancer cell, the blood was inserted in the Tf-NMSFGC flow channel and rolled inside the capillary for $5 \mathrm{~min}$ in order to initiate the blood and $\mathrm{Fe}_{3} \mathrm{O}_{4}$-GSH-PEG-Tf interaction. After 5 min the sample was collected from the capillary using micropipette and transferred to another Tf-NMSFGC and again rolled inside it for another $5 \mathrm{~min}$. This procedure was repeated one more time. The blood sample was then collected in 96-well plates using micropipette. The capillaries were rinsed with PBS at least three times to get rid of unattached cells. The number of uncaptured cells was counted using the fluorescence microscope.

Characterization: TEM analysis was performed using a Philips (CM 200) TEM machine set at an accelerating voltage of $200 \mathrm{kV}$. Samples for TEM were prepared by placing a drop of the $\mathrm{Fe}_{3} \mathrm{O}_{4}$-GSH-PEG-Tf suspension in deionized water on a Formvar-covered copper grid and then evaporating the water at room temperature. Conjugation of protein (Tf) to $\mathrm{Fe}_{3} \mathrm{O}_{4}$-GSH-PEG was confirmed by a modified Bradford assay. Fluorescence imaging and counting of cells were performed using Zeiss Axio Observer Almiscroscope (Carl Zeiss, Jena, Germany).

\section{Supporting Information}

Supporting Information is available from the Wiley Online Library or from the author.

\section{Acknowledgements}

The authors would like to acknowledge the financial support from the Biotechnology Ignition Grant (BIG), Biotechnology Industry Research Assistance Council (BIRAC), Department of Biotechnology (DBT). J.J.K. acknowledges nanobiotechnology research grant from the Department of Biotechnology and funds for improvement of science and technology infrastructure from the Department of Science and Technology (FIST-DST).

Received: September 29, 2016

Revised: November 15, 2016

Published online: January 18, 2017

[1] K. Pantel, R. H. Brakenhoff, B. Brandt, Nat. Rev. Cancer 2008, 8, 329.

[2] S. S. Banerjee, A. Jalota-Badhwar, S. D. Satavalekar, S. G. Bhansali, N. D. Aher, R. R. Mascarenhas, D. Paul, S. Sharma, J. J. Khandare, Adv. Healthcare Mater. 2013, 2, 800.

[3] J. Kaiser, Science 2010, 327, 1074.

[4] S. S. Banerjee, A. Jalota-Badhwar, K. R. Zope, K. J. Todkar, R. R. Mascarenhas, G. P. Chate, G. V. Khutale, A. Bharde, M. Calderon, J. J. Khandare, Nanoscale 2015, 7, 8684.

[5] K. Pantel, R. H. Brakenhoff, Nat. Rev. Cancer 2004, 4, 448.

[6] A. H. Kuo, M. F. Clarke, Nat. Biotechnol. 2013, 31, 504.

[7] C. A. Klein, Science 2008, 321, 1785.

[8] S. Nagrath, L. V. Sequist, S. Maheswaran, D. W. Bell, D. Irimia, L. Ulkus, M. R. Smith, E. L. Kwak, S. Digumarthy, A. Muzikansky, P. Ryan, U. J. Balis, R. G. Tompkins, D. A. Haber, M. Toner, Nature 2007, 450, 1235.

[9] E. I. Galanza, E. V. Shashkov, T. Kelly, J. W. Kim, L. Yang, V. P. Zharov, Nat. Nanotechnol. 2009, 4, 855.

[10] Q. Shen, L. Xu, L. Zhao, D. Wu, Y. Fan, Y. Zhou, W. H. OuYang, X. Xu, Z. Zhang, M. Song, T. Lee, M. A. Garcia, B. Xiong, S. Hou, H. R. Tseng, X. Fang, Adv. Mater. 2013, 25, 2368.

[11] A. H. Talasaz, A. A. Powell, D. E. Huber, J. G. Berbee, K. H. Roh, W. Yu, W. Xiao, M. M. Davis, R. F. Pease, M. N. Mindrinos, S. S. Jeffrey, R. W. Davis, Proc. Natl. Acad. Sci. USA 2009, 106, 3970.

[12] A. Adams, P. I. Okagbare, J. Feng, M. L. Hupert, D. Patterson, J. Gttert, R. L. McCarley, D. Nikitopoulos, M. C. Murphy, S. A. Soper, J. Am. Chem. Soc. 2008, 130, 8633.

[13] S. Wang, K. Liu, J. Liu, Z. T. F. Yu, X. Xu, L. Zhao, T. Lee, E. K. Lee, J. Reiss, Y. K. Lee, L. W. K. Chung, J. Huang, M. Rettig, D. Seligson, 
K. N. Duraiswamy, C. K. F. Shen, H. R. Tseng, Angew. Chem. Int. Ed. 2011, 50, 3084.

[14] S. Zheng, H. Lin, J. Q. Liu, M. Balic, R. Datar, R. J. Cote, Y. C. Tai, J. Chromatogr. A 2007, 1162, 154.

[15] Z. A. Nima, M. Mahmood, Y. Xu, T. Mustafa, F. Watanabe, D. A. Nedosekin, M. A. Juratli, T. Fahmi, E. I. Galanzha, J. P. Nolan, A. G. Basnakian, V. P. Zharov, A. S. Biris, Sci. Rep. 2014, 4, 4752.

[16] G. Vona, A. Sabile, M. Louha, V. Sitruk, S. Romana, K. Schutze, F. Capron, D. Franco, M. Pazzagli, M. Vekemans, B. Lacour, C. Brechot, P. Paterlini-Brechot, Am. J. Pathol. 2000, 156, 57.

[17] S. S. Banerjee, D. Paul, S. G. Bhansali, N. D. Aher, A. Jalota-Badhwar, J. Khandare, Small 2012, 8, 1657.
[18] E. Reátegui, N. Aceto, E. J. Lim, J. P. Sullivan, A. E. Jensen, M. Zeinali, J. M. Martel, A. J. Aranyosi, W. Li, S. Castleberry, A. Bardia, L. V. Sequist, D. A. Haber, S. Maheswaran, P. T. Hammond, M. Toner, S. L. Stott, Adv. Mater. 2015, 27, 1593.

[19] J. S. Miller, K. R. Stevens, M. T. Yang, B. M. Baker, D. H. T. Nguyen, D. M. Cohen, E. Toro, A. A. Chen, P. A. Galie, X. Yu, R. Chaturvedi, S. N. Bhatia, C. S. Chen, Nat. Mater. 2012, 11, 768.

[20] G. Yang, Y. Cao, J. Fan, H. Liu, F. Zhang, P. Zhang, C. Huang, L. Jiang, S. Wang, Angew. Chem., Int. Ed. 2014, 53, 2915.

[21] S. S. Banerjee, D. H. Chen, Chem. Mater. 2007, 19, 6345.

[22] S. Noel, B. Liberelle, L. Robitaille, G. De Crescenzo, Bioconjugate Chem. 2011, 22,1690. 